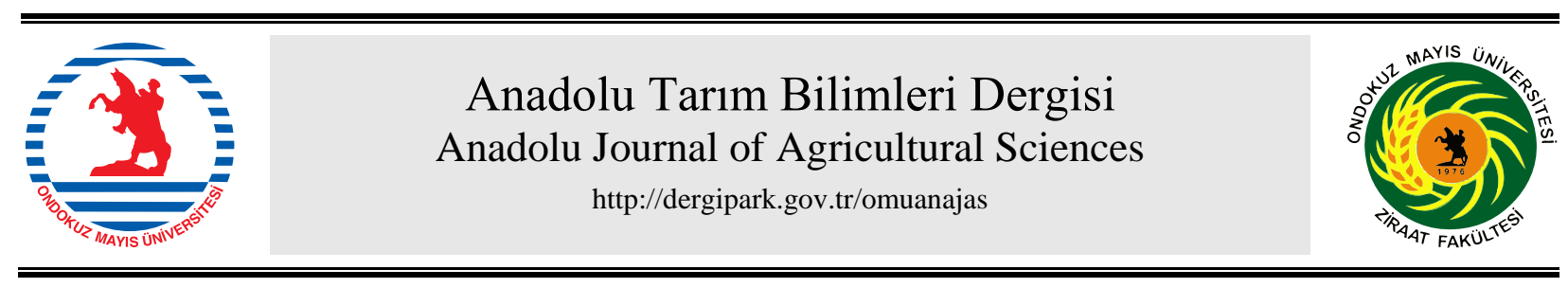

Araştırma/Research

Anadolu Tarım Bilim. Derg./Anadolu J Agr Sci, 33 (2018) ISSN: 1308-8750 (Print) 1308-8769 (Online) doi: 10.7161/omuanajas.342904

\title{
Mikrodalga firın ile kurutulan yenidünya (Eriobotrya japonica L.) meyvesinin kuruma kinetiği ve kalitesinin belirlenmesi
}

\author{
Hakan Polatc1 *, Muhammed Taşova \\ Gaziosmanpaşa Üniversitesi Ziraat Fakültesi Biyosistem Mühendisliği Bölümü \\ *Sorumlu yazar/corresponding author: hakan.polatci@gop.edu.tr
}

Geliş/Received 11/10/2017～Kabul/Accepted 25/02/2018

\begin{abstract}
ÖZET
Yeni dünya meyvesinin doku yapısının hassas ve nem içeriğinin yüksek olmasından dolayı bozulmadan uzun süre depolanamamaktadır. Bu çalışmada mikrodalga yöntemi ile kurutulan yenidünya meyvesinin kuruma kinetiği ve renk kriteri açısından en uygun son kalite değerinin belirlenmesi amaçlanmıştır. Ürün 360, 540, 720 ve $900 \mathrm{~W}$ güçlerinde kurutulara yenidünya meyvesinin kuruma performans değerleri, en uygun ince tabakalı kuruma modeli, efektif difüzyon değeri ve renk değerleri belirlenmiştir. Ürün nemi yaş baza göre \% 10-13 aralığına düşene kadar kurutulmuş ve ortalama kuruma süreleri 360, 540, 720 ve 900W güç değerleri için sırasıyla 28, 15.5, 12 ve 10 dakika olarak belirlenmiştir. Kuruma sırasında üründen uzaklaşan birim zamandaki nem değerleri ince tabakalı kurutma modellerinde işlenerek kuruma eğrilerini en iyi tahmin eden matematiksel model belirlenmiştir. Eğriler oluşturulurken literatürde de en yaygın olarak kullanılan Page, Midilli-küçük, Yağcıŏlu ve Modified-Page modelleri seçilmiştir. Kullanılan tüm modellerin güvenilirlik değerleri $\mathrm{p}<0,05$ olarak belirlenmiştir. Belirlenen $\mathrm{R}^{2}$ değerleri içerisinde 1'e en yakın olan eşitlik kuruma eğrilerini en iyi tahmin ince tabakalı matematiksel model olarak kabul edilmiştir. Uygulanan kuruma modelleri içerisinde en iyi tahmin eden ince tabakalı kuruma modelleri 360, 540, 720 ve 900W güç değerleri için sırasıyla Midilli-küçük (0.9996), Midilli-küçük (0.9991), Midilli-küçük (0.9989) ve Midilli-küçük (0.9983) olarak belirlenmiştir. Yenidünya meyvesine uygulanan tüm kurutma şartları içerisinde Midilli-küçük modeli en uygun ince tabakalı matematiksel model olarak belirlenmiştir. Kurutma işlemlerinde belirlenen efektif difüzyon (Deff) değerleri ise $2.28 \times 10^{-6}$ ile $6.66 \times 10^{-6} \mathrm{~m}^{2} \mathrm{~s}^{-1}$ aralığında değiştiği belirlenmiştir. Yenidünya meyvesi için ticari açıdan önemli bir renk değeri olan kroma değeri taze ürünün kroma değerine en yakın $360 \mathrm{~W}$ güçte yapılan kurutma işleminde belirlenmiştir.
\end{abstract}

The effects of safflower meal on the performance, egg quality traits, yolk fatty acids and cholesterol levels in laying hens

\footnotetext{
ABSTRACT

Because of the texture of the japanese medlar is a fruit sensitive and high moisture content which cannot be stored for a long time without deterioration. In this study was aimed to determine the most suitable final quality value in terms of drying kinetics and color criterion of japanese medlar fruit dried by microwave method. Drying performance values, optimum thin layer drying curve, effective diffusion and color values of japanese medlar fruit dried at 360, 540, 720 and 900W with microwave were determined in the study. The mean dry times of the japanese medlar dried up to an average of $10-13 \%$ by wet weight were determined as 28,15.5, 12 and 10 minutes at 360, 540, 720 and $900 \mathrm{~W}$, respectively. Moisture values that drift away from the unit during the first nip during drying are processed in thin layer drying equations and a mathematical model which predicts drying curves best is determined. When creating curves, the most commonly used Page, Midilli-Küçük, Yağcığlu and Modified-Page models were chosen. The usability of all used models was found to be appropriate and the reliability values were determined as $\mathrm{p}<0.05$. The best estimate of equilibrium drying curves, which is closest to 1 in the determined $\mathrm{R}^{2}$ values, is determined as a thin layered mathematical model. The best estimating thin layer drying models are for Midilli-Küçük (0.9996), Midilli-Küçük (0.9991), Midilli-Küçük (0.9989), and Midilli-Küçük for the values of $360,540,720$ and $900 \mathrm{~W}$ respectively (0.9983). In the thin layer drying models of japanese medlar, the Midilli-Küçük model was determined to be the most suitable for all drying conditions. The
}

Anahtar Sözcükler: Yenidünya Kurutma Kuruma performans1 Efektif difüzyon ve renk değerleri
Keywords:

Japanese medlar Drying

Drying performance Effective diffusion and color values 
effective diffusivity (Deff) values determined under the drying conditions were determined to vary between $2.28 \times 10^{-6}$ and $6.66 \times 10^{-6} \mathrm{~m}^{2} \mathrm{~s}^{-1}$. It was determined that japanese medlar received the most chromium value for the commercial value of the chrome value fresh fruit in the drying process of $360 \mathrm{~W}$ power value.

\section{Giriş}

Yenidünya meyvesi (Eriobotrya japonica L.) çok eski zamanlardan bir çok kimse tarafindan beğenilen fakat yaygın bir şekilde tüketilmemesine rağmen içerdiği besin ve tıbbi değerleri açısından her zaman ilgi çeken bir meyve olmuştur (Zhou ve ark., 2007; Cao ve ark., 2009). Rosaceae ailesinden olan yenidünya meyvesi yaygin olarak oval, yuvarlak şekillerde ve sarı, turuncu renklerde yetişmektedir (Lin ve ark., 1999; Ercişli ve ark., 2012).

Yenidünya meyvesi dünya üzerinde genelde 1lıman iklime sahip bölgelerde yetişmesine rağmen daha çok Çin, Japonya, Hindistan, Pakistan, Kıbrıs, Mısır, Yunanistan, Tunus ve Türkiye'de yetișmektedir (Lin, 2008; Pareek ve ark., 2014). Meyvenin kendine özgü tatlılığ1 ve kokusunun yanında karatoneid, fenolik bileşikler, mineraller ve zengin vitamin değerlerini içermesinden dolayı özel bir tropik meyvedir (Xu ve Chen, 2011).Yenidünya meyvesi sağlık açısından iltihap söktürücü, tümör oluşumunu engelleyici ve hipoglisemik gibi hastalıkların yanında bronşit ve böbrek rahatsılıklarının tedavisinde önemli etkisinin olduğu bilinmektedir (Singh ve ark., 2010).Yüksek nem içeriğine sahip yaş sebze ve meyveler besin değerlerini uzun süre muhafaza edemediğinden dolayı kısa süre içerisinde bozulmaktadırlar. Karim ve Hawalder (2005)'e göre özellikle gelişmekte olan ülkelerde uygun muhafaza ortamlarının yetersizliğinden dolayı taze ürünlerin yaklaşık \% 30-40'ı bozulup çöpe atılmaktadır.

Yaş baza göre ortalama \% 85-90 civarında yüksek bir nem içeriğine sahip olan yenidünya meyvesi kendine özgü doku yapısından dolayı hasat sonras1 $20-25{ }^{\circ} \mathrm{C}$ sicaklıktaki bir ortamda ancak 10 gün kadar bozulmadan kalabilmektedir (Yang ve ark., 2008). Bu nedenle ürün içerisinde bulunan yüksek nemin büyük bir kısmı kontrollü bir şekilde uzaklaştırılması gerekmektedir. Bundan dolayı hem ilk yatırım maliyeti ve enerji tüketimi açısından ekonomik olması hem de ürünün uzun süre bozulmadan kalabilmesi açısından genelde ürünler kurutularak muhafaza edilmesi daha yaygındır.

Kurutma işlemi tarımsal ürünlerin uzun süre saklanması için tercih edilen en eski yöntemlerden biri olup, üründeki nemin büyük bir kısmın uzaklaştırıldığı aynı zamanda da ürününsu aktivitesi değerinin düşürülerek mikroorganizma faaliyetlerin çoğalması engellenmekte ve ürünün raf ömrü uzatılmaktadır (Pisalkar ve ark., 2011). Ürünlerin kurutulması için genel olarak doğal kurutma ve zorlanmış sıcak hava ile yapılan kurutma yöntemleri tercih edilmektedir. Ancak bu kurutma yöntemlerinde kuruma işlemi uzun sürmekte ve bundan dolayı da ürün uzun süre 1sıya maruz kalmaktadır. Bu şekilde hem enerji tüketimi hem de kurutulan materyalin kalite değerleri açısından bazı olumsuzluklar oluşmaktadır. Bu nedenle kurutma işleminin daha kısa sürede ve daha az enerji tüketerek gerçekleşmesi gerekmektedir. Bunun yanında da kurutulmuş son ürünün doku, renk ve fitokimyasal özelliklerinden az kayba neden olan kurutma yöntemleri tercih edilmelidir.

Mikrodalga ile yapılan kurutma işlemleri diğer kurutma yöntemlerine göre daha kısa sürede kurutma, daha az enerji tüketimi ve son ürünün kalite değerlerinde daha fazla korumanın gerçekleşmesine neden olmaktadır. Literatürde yeni dünya meyvesi ile ilgili Akhtar (2010), depolama süresinde kalsiyum klorit uygulamasının meyvenin kalitesine olan etkisinin belirlenmesi, Ghasemnzhad ve ark. (2011), kitosan uygulamasının yenidünya meyvesinin hasat sonras1 kalitesine olan etkisinin belirlenmesi, Shao ve ark. (2013), yenidünya meyvesinin soğukta depolama esnasında 1sı etkili soğuma toleransının çözülebilir şeker içeriğine ve metabolizmasına olan etkisinin belirlenmesi, Abbasi ve ark. (2013), hasat sonras1 yenidünya meyvesinin kalitesinin devam ettirilebilirliği, Xu ve ark. (2014), altı çeşit yenidünya meyvesinin fenolik bileşikleri ile antioksidan kapasiteleri açısından kıyaslanması gibi konular çalışılmıştır. Ancak yenidünya meyvesinin bazı kuruma özelliklerinin ve uygun kurutma koşulunun belirlenmesi konusunda çok sınırlı sayıda çalışmayla karşılaşılmıştır.

$\mathrm{Bu}$ nedenle çalışmada mikrodalgada dört farklı güç değeri uygulanarak kesikli kurutma şeklinde yapılan kurutma işlemlerinde yenidünya meyvesinin kuruma kinetikleri, kuruma sonrasındaki ürünün en uygun renk değerleri,kuruma eğrilerini en iyi tahmin eden ince tabakalı kurutma modelleri ve ürünün kuruma esnasındaki efektif difüzyon değerleri belirlenmiştir.

\section{Materyal ve Yöntem}

\subsection{Kurutulacak ürün}

Çalışmada kullanılan yenidünya meyvesi Tokat'ta bulunan yerel bir pazardan satın alındiktan sonra Gaziosmanpaşa Üniversitesi Biyosistem Mühendisliği bölümü kurutma laboratuvarına getirilmiştir. Kurutma işlemleri tamamlanana kadar ürün $+4 \pm 0.5^{\circ} \mathrm{C}$ sicaklığa ayarlanmış buz dolabında saklanmıştır.

\subsection{Nem tayini}

Taze yenidünya meyvesinin nem içeriğini belirlemek için dörder tekerrür şeklinde gerçekleştirilmiş ve her tekerrürde ortalama 40'ar gr örnek kullanılmıştır. Nem tayini $70 \quad{ }^{\circ} \mathrm{C}$ sıcaklığa ayarlanmış etüvde belirli aralıklarda ürünler tartılarak ağırlıklarındaki değişim 
sabitlenene kadar kurutulmuştur (Yağcıoğlu, 1999).

\subsection{Kurutma yöntemi}

Kurutma işlemine başlamadan önce materyal yıkandıktan sonra kötü olan meyveler ayıklanmıştır. Daha sonra meyveler ikiye bölünerek çekirdekleri çıkartılmıştır. Kurutma işlemleri güç değeri ve bekletme süresi ayarlanabilir bir mikrodalga kurutucuda, 360, 540 ve 720, $900 \mathrm{~W}$ güç değerlerinde gerçekleştirilmiştir. Kurutma işlemleri 3 'er tekerrür şeklinde yapılarak ve her tekerrürde ortalama $70 \pm 1,0$ g kadar ürün kullanılmıştır. Kurutma işlemlerinde belirli süre aralıklarında 0,01 hassasiyete sahip bir hassas terazi ile ürün ağırlıkları tartılmıştır. Ürün nemi yaş baza göre \% 10-13 seviyesinedüşene kadar kurutma işlemine devam edilmiştir.

\subsection{Mikrodalga kurutucu}

$\mathrm{Bu}$ çalışmada Vestel marka ve MD-GD23 model mikrodalga firın kullanılmıştır. Mikrodalga firın toplam 900 W çıkış gücüne sahip olup boyutları yükseklik $\times$ genişlik $\times$ derinlik değerleri sırasıyla $305 \mathrm{~mm}$ $\times 508 \mathrm{~mm} \times 385 \mathrm{~mm}$ 'dir. Ayrıca ürünler firın içerisinde bulunan döner bir cam tabak üzerinde kurutulmuştur.

\subsection{Renk ölçümü}

Taze ve kurutulmuş yenidünya meyvesininL, a, b birincil renk değerleri ölçülmüştür. Renk ölçümleri için Minolta marka CR300 model renk ölçer kullanılmıștır. L, a ve $b$ değerleri ürünlerin renkleri hakkında bazı bilgiler vermektedir. Bunlar;" L " materyalin parlaklık değerini ifade ederken 0-100 arasında değerler almaktadır. L değeri 0 olduğunda siyah rengi yani yansımanın hiç olmadığını, L değeri 100 olduğunda ise ürün renginin beyaz olduğunu yani yansımanın tam olduğunu ifade etmektedir. " a " kırmızı - yeşil, " b " sarı - mavi renkleri ifade ederken sırasıyla $(+,-)$ değerleri almaktadır. Renk değerleri $\mathrm{a}=0$ ve $\mathrm{b}=0$ olduğu durumda ise ürün renginin gri olduğunu ifade etmektedir (McGuire, 1992).

Bir başka renk değeri olan kroma ise rengin tonunu ifade etmektedir.Solgun renklerde kroma değeri düşük değerler alırken canlı renklerde ise yüksek değerler almaktadır. Kroma değeri ve Hue açısı değerleri 1 ve 2 numaralı eşitlikler kullanılarak hesaplanmaktadır.

$$
\begin{aligned}
& \mathrm{C}=\left(\mathrm{a}^{2}+\mathrm{b}^{2}\right)^{1 / 2} \\
& \mathrm{~h}^{\circ}=\tan ^{-1}\left(\frac{\mathrm{b}}{\mathrm{a}}\right)
\end{aligned}
$$

Kahverengilik indeks değeri olan " BI " ile " $\mathrm{x}$ " değerleri ise 3 ve 4 numaralı eşitlikler kullanılarak hesaplanmaktadir.

$$
\mathrm{BI}=\frac{[100(\mathrm{x}-0,31)]}{0,17}
$$

$$
x=\frac{a+(1,75 x L)}{[(5,645 \times L)+(a-(3,012 \times b))]}
$$

\subsection{Kuruma modeli}

Kurutulan yenidünya meyvesinin zamana bağl1 olarak ayrılan nem oranı değeri 5 numaralı eşitlik kullanılarak belirlenmiştir.

$$
\mathrm{ANO}=\frac{\mathrm{M}-\mathrm{M}_{\mathrm{e}}}{\mathbf{M}_{\mathrm{o}}-\mathrm{M}_{\mathrm{e}}}
$$

ANO: Ayrılabilir nem oranı

M: Kurutulan materyalin anlık nem içeriği

Me: Kurutulan materyalin verilen durumdaki denge nemi

Mo: Kurutulan materyalin ilk nem içeriği

$$
M R=\frac{M-M_{e}}{M_{0}-M_{e}}=\frac{8}{\pi} \sum_{n=0}^{\infty} \frac{1}{(2 n+1)^{2}} \exp \left[(2 n+1)^{2} \frac{\pi^{2}}{4} \frac{D_{e f f} t}{L^{2}}\right](6)
$$

Kuruma eğrilerini oluşturmak için yaygın olarak kullanılan Page, Midilli - Küçük, Yağcıoğlu ve Modified-Page matematiksel modelleri seçilmiştir. Modellerin eşitlikleri Çizelge 1'de verilmiştir.

Çizelge 1. Ínce tabakalı kuruma modelleri

\begin{tabular}{ccc}
\hline No & Model İsmi & Eşitlik \\
\hline 1 & Page & MR $=\exp \left(-\mathrm{h} .\left(\mathrm{t}^{\mathrm{j}}\right)\right)$ \\
2 & Midilli küçük & $\mathrm{MR}=\mathrm{h} \cdot \exp \left(-\mathrm{j} \cdot\left(\mathrm{t}^{\mathrm{k}}\right)\right)+(1 . \mathrm{t})$ \\
3 & Yağcıŏlu & $\mathrm{MR}=\mathrm{k} \cdot \exp (-\mathrm{h} \cdot \mathrm{t})+\mathrm{j}$ \\
4 & Modified-Page & $\mathrm{MR}=\exp \left(-(\mathrm{k} \cdot \mathrm{t})^{\mathrm{h}}\right)$ \\
\hline
\end{tabular}

\subsection{Efektif difüzyon değerinin (Deff, $m^{2} s^{-1}$ ) belirlenmesi}

Üründen nemin uzaklaşması Fick yasasının ikinci kanunu olan süreye bağlı olarak uzaklaştığı alan miktarı diğer bir adı ile efektif difüzyon değeri belirlenmiştir. Efektif difüzyon değeri belirlenirken ürünün doku yapısının korunduğu ve nemin sadece difüzyon ile ortamdan uzaklaştığı varsayımı kabul edilerek 6 numaralı eşitlik kullanılarak hesaplanmıştır (Crank, 1979).Eşitlikte Deff efektif difüzyon değerini $\left(\mathrm{m}^{2} \mathrm{~s}^{-1}\right), \mathrm{L}$ değeri ürünün dilim kalınlığının yarısını ifade etmektedir. Çalışmada mikrodalga fırında yapılan kurutma işlemlerinde difüzyon tek yönlü gerçekleşmiştir. 6 numaralı eşitlik matematiksel kurallara göre düzenlendikten sonra 7 numaralı eşitlik elde edilmiştir.

$$
\operatorname{In} M R=\operatorname{In} \frac{8}{\pi^{2}}-\frac{\pi^{2} D_{e f f} t}{4 L^{2}}
$$

Belirlenen boyutsuz nem oranı (MR) değerleri kuruma süresine göre bir doğru oluşturulduğunda doğrunun eğiminden her güç değerleri için ayrı ayrı Deffdeğerleri hesaplanmıştır (Zakipour ve Hamidi, 2011). 


\section{Bulgular ve Tartışma}

\subsection{Kuruma verileri}

Yenidünya meyvesinin ortalama nem içeriği yaş baza göre \% 89,70 olarak belirlenmiştir. Kurutma işlemlerinde ürünün nem içeriği yaş baza göre \% 10-13 aralığına düşene kadar kurutulmuştur.

Ürünün kurutma şartları altında belirlenen ortalamakuruma değerleri, renk değerleri, ince tabakalı kurutma modellerine ait sayısal değerler ve kurutma işlemlerinde belirlenen efektif difüzyon değerleri çizelgelerde verilmiştir. Uygulanan güç değerlerinin ürünün kuruma performansını etkilediği ve güç değerinin artmasıyla da kuruma sürelerinin azaldığı belirlenmiştir (Çizelge 2). Kaya ve ark. (2015), Trabzon hurmasının kuruma özelliklerinin belirlenmesi konulu çalışmalarında kurutma sıcaklığının artması ile kuruma oranının artığı ve kuruma süresinin kısaldığını ifade etmişılerdir. Taşova (2016), sıcaklık kontrollü mikrodalga kullanarak gerçekleştirdiği elma kurutma çalışmasında kurutma sıcaklığının artması ile kuruma süresinin azaldığını ifade etmiştir. Yoğurtçu (2016), 90-600 W güç değerinde değişen kurutma şartlarında kuruttuğu Tunceli sarımsağının kuruma sürelerinin güç değerinin artması ile kuruma sürelerinde önemli seviyede bir azalmanın olduğunu ifade etmiştir. Çelen ve ark. (2017), elma dilimlerinin farklı mikrodalga güçlerinde yaptığ kurutma çalışmasında güç değerinin artması ile kuruma sürelerinde bir azalmanın gerçekleştiğini ifade etmişlerdir.

\subsection{Kuruma modellerinin tahminleme başarıs}

Kurutma işlemlerinde süreye bağlı ayrılabilir boyutsuz nem oranlarını belirlemek için kuruma eğrileri oluşturulmuştur. Kuruma eğrilerine ait katsayılar, varyans analiz değerleri (p) vemodellerin kararlılık katsayısı (R2) değerleri Çizelge 3, 4, 5 ve 6'da verilmiştir. Uygulanan tüm kurutma şartlarında modellerin kullanılabilirliğinin güvenilir $(p<0,05)$ olduğu belirlenmiştir. Modellere ait belirlenen en yüksek $\mathrm{R}^{2}$ değerleri hepsinde de $360 \mathrm{~W}$ güç değerinde belirlenmiştir. Yapılan bu çalışmada yenidünya meyvesinin kuruma eğrilerini en iyi tahmin eden ince tabakalı matematiksel kuruma modelin Midilli-Küçük olduğu belirlenmiştir.

\subsection{Renk değerleri}

Taze ve kurutulmuş yenidünya meyvesine ait L, a, b değerleri ölçülerek ikincil renk değerleri olan kroma, hue açısı ve kahverengileşme indeks değerleri hesaplanmıştır. Ayrıca taze ve kurtulmuş yenidünya meyvesine ait ölçülen ve hesaplanan renk değerlerinin istatistiksel açıdan aralarında farkın olup olmadığını belirlemek için Duncan testi uygulanmıştır (Çizelge 7).

Çizelge7'e göre taze materyalin parlaklık (L) değerine göre tüm güç değerlerinde ölçülen kuru ürünün parlaklık değerleri azalmıştır. Tazeye göre L değerinin en az 900 $\mathrm{W}$ güç değerinde korunduğu belirlenirken en az fazla korunmanın ise $360 \mathrm{~W}$ güç olduğu belirlenmiştir. Bunun nedeninin yüksek güç değerinde ürün hızlı kuruyarak renk değerini muhafaza edemediği düşünülmektedir. Alibaş (2012a), mikrodalga ile üç farklı güç yoğunluğunda kuruttuğu asma yaprağının tazeye göre L renk değerindeki en fazla değişim uygulanan en yüksek güç yoğunluğunda belirlendiğini ifade etmiştir. Çelen (2010), farklı güç seviyelerinde uygulanan kurutma şartlarının domates ve elmanın L renk değerlerinde tazeye göre en fazla uzaklaşmanın en yüksek güç değerlerinde tespit ettiğini ifade etmiştir.

Çizelge 2. Yenidünya meyvesinin kuruma performans değerleri

\begin{tabular}{ccc}
\hline Güç Değerleri & Ortalama Son Nem Değerleri (\%) & Kuruma Süreleri (dk) \\
\hline $360 \mathrm{~W}$ & $\% 10.15$ & 28 \\
$540 \mathrm{~W}$ & $\% 10.05$ & 15.5 \\
$720 \mathrm{~W}$ & $\% 10.00$ & 12 \\
$900 \mathrm{~W}$ & $\% 11.00$ & 10 \\
\hline
\end{tabular}

Çizelge 3.Page eşitliğine ait katsayılar, " $\mathrm{R}^{2}$ ” ve “p " değerleri

\begin{tabular}{ccccc}
\hline Mikrodalga ile Kurutma & $\mathrm{k}$ & $\mathrm{h}$ & $\mathrm{R}^{2}$ & $\mathrm{p}$ \\
\hline $360 \mathrm{~W}$ & 0.0148 & 1.6354 & 0.9991 & $<0.0001$ \\
$540 \mathrm{~W}$ & 0.0378 & 1.6277 & 0.9981 & $<0.0001$ \\
$720 \mathrm{~W}$ & 0.0591 & 1.6650 & 0.9986 & $<0.0001$ \\
$900 \mathrm{~W}$ & 0.0705 & 1.7258 & 0.9982 & $<0.0001$ \\
\hline
\end{tabular}


Çizelge 4. Midilli-Küçük eşitliğine ait katsayılar, " ${ }^{2}$ " ve " $p$ " değerleri

\begin{tabular}{ccccccc}
\hline Mikrodalga ile Kurutma & $\mathrm{k}$ & $\mathrm{h}$ & $\mathrm{j}$ & $\mathrm{m}$ & $\mathrm{R}^{2}$ & $\mathrm{p}$ \\
\hline $360 \mathrm{~W}$ & 1.5353 & 1.0082 & 0.0179 & -0.0013 & 0.9996 & $<0.0001$ \\
$540 \mathrm{~W}$ & 1.5010 & 1.0151 & 0.0452 & -0.0031 & 0.9991 & $<0.0001$ \\
$720 \mathrm{~W}$ & 1.6071 & 1.0137 & 0.0655 & -0.0006 & 0.9989 & $<0.0001$ \\
$900 \mathrm{~W}$ & 1.6836 & 1.0077 & 0.0747 & -0.0009 & 0.9983 & $<0.0001$ \\
\hline
\end{tabular}

Çizelge 5. Yağcığlu eşitliğine ait katsayılar, “ $R^{2}$ ” ve “p ” değerleri

\begin{tabular}{cccccc}
\hline Mikrodalga ile Kurutma & $\mathrm{k}$ & $\mathrm{h}$ & $\mathrm{j}$ & $\mathrm{R}^{2}$ & $\mathrm{p}$ \\
\hline $360 \mathrm{~W}$ & 1.6842 & 0.0359 & -0.6309 & 0.9924 & $<0.0001$ \\
$540 \mathrm{~W}$ & 1.7484 & 0.0606 & -0.6919 & 0.9909 & $<0.0001$ \\
$720 \mathrm{~W}$ & 1.5126 & 0.1055 & -0.4442 & 0.9862 & $<0.0001$ \\
$900 \mathrm{~W}$ & 1.6113 & 0.1123 & -0.5478 & 0.9818 & $<0.0001$ \\
\hline
\end{tabular}

Çizelge 6. Modified-Page eşitliğine ait katsayılar, “ $\mathrm{R}^{2}$ ” ve “ $\mathrm{p}$ ” değerleri

\begin{tabular}{ccccc}
\hline Mikrodalga ile Kurutma & $\mathrm{k}$ & $\mathrm{h}$ & $\mathrm{R}^{2}$ & $\mathrm{p}$ \\
\hline $360 \mathrm{~W}$ & 0.0760 & 1.6354 & 0.9991 & $<0.0001$ \\
$540 \mathrm{~W}$ & 0.1337 & 1.6278 & 0.9981 & $<0.0001$ \\
$720 \mathrm{~W}$ & 0.1829 & 1.6649 & 0.9986 & $<0.0001$ \\
$900 \mathrm{~W}$ & 0.2150 & 1.7258 & 0.9982 & $<0.0001$ \\
\hline
\end{tabular}

Çizelge 7.Renk değerlerine ait Duncan test sonuçları

\begin{tabular}{ccccccc}
\hline Kurutma Şartlar1 & $\mathrm{L}^{*}$ & $\mathrm{a}^{*}$ & $\mathrm{~b}^{*}$ & $\mathrm{C}^{*}$ & $\mathrm{~h}^{\text {o* }}$ & $\mathrm{BI}^{*}$ \\
\hline Taze & $45.56^{\mathrm{a}}$ & $9.73^{\mathrm{b}, \mathrm{c}}$ & $14.90^{\mathrm{a}}$ & $17.8^{\mathrm{b}}$ & $56.63^{\mathrm{a}}$ & $55.93^{\mathrm{b}}$ \\
$360 \mathrm{~W}$ & $42.15^{\mathrm{a} . \mathrm{b}}$ & $13.1^{\mathrm{a}}$ & $17.22^{\mathrm{a}}$ & $21.80^{\mathrm{a}}$ & $51.87^{\mathrm{a}}$ & $74.36^{\mathrm{a}}$ \\
$540 \mathrm{~W}$ & $38.28^{\mathrm{b}, \mathrm{c}}$ & $10.68^{\mathrm{b}}$ & $7.9^{\mathrm{b}}$ & $13.37^{\mathrm{c}}$ & $35.70^{\mathrm{b}}$ & $42.73^{\mathrm{c}}$ \\
$720 \mathrm{~W}$ & $38.18^{\mathrm{b}, \mathrm{c}}$ & $10.31^{\mathrm{b}}$ & $8.37^{\mathrm{b}}$ & $13.76^{\mathrm{c}}$ & $32.35^{\mathrm{b}}$ & $43.67^{\mathrm{b}, \mathrm{c}}$ \\
$900 \mathrm{~W}$ & $34.80^{\mathrm{c}}$ & $8.52^{\mathrm{c}}$ & $6.34^{\mathrm{b}}$ & $11.83^{\mathrm{c}}$ & $18.10^{\mathrm{c}}$ & $34.53^{\mathrm{c}}$ \\
\hline
\end{tabular}

Taze ürüne göre kırmızılık değerinin en az360 W güç değerinde korunduğu belirlenirken en fazla korunduğu güç değerinin ise $900 \mathrm{~W}$ olmuştur. Düşük güç değerinde yapılan kurutma işlemi ürünün kırmızılık değerinin muhafazasına olumsuz etki ederken yüksek güç değerinde yapılan kurutma işleminin ise olumlu etki ettiği belirlenmiştir. Taze ürüne göre sarılık değerinin en az $900 \mathrm{~W}$ güç değerinde korunduğu belirlenirken en fazla korunduğu güç değerinin ise $360 \mathrm{~W}$ olmuştur. Yüksek güç değerinde yapılan kurutma işlemi ürünün sarılık değerinin muhafazasına olumsuz etki ederken düşük güç değerinde yapılan kurutma işleminin ise olumlu etki ettiği belirlenmiştir.

Kurutulmuş ürünlerin kroma değerlerinin taze ürünün kroma değerine göre tüm kurutma güç değerlerinde uzaklaştığ 1 belirlenmiştir. Taze ürüne göre kuru ürünlerin kroma değerinde en fazla uzaklaşma $900 \mathrm{~W}$ güç değerinde gerçekleşmiştir. Bunun nedeni $a$ ve $b$ değerlerinde oluşan değişim diğer kurutma şartlarına göre daha fazla gerçekleşmiş olmasıdır. Alibaş (2012b), mikrodalga ile yaptığı çilek kurutması çalışmasında güç değerinin artması ile kroma değerinin azaldı ̆̆ını ifade etmiştir. Alibaş (2015), mikrodalga ile mango dilimlerinin kurutulması çalışmasında uygulanan en yüksek güç değerinde tazeye göre kroma değerinde en fazla uzaklaşmanın gerçekleştiği kurutma şartı olarak belirlenmiştir.

Taze ürünün hue renk değerinden en fazla uzaklaşmanın $900 \mathrm{~W}$ güç değerinde yapılan kurutma işlemi olurken en az uzaklaşmanın ise $360 \mathrm{~W}$ güç 
değerinde yapılan kurutma işlemi olduğu belirlenmiştir. Taze ürünün kahverengileşme değerine göre uygulanan güç değerlerinin hepsinde bir değişme gerçekleşmiştir. Taze ürüne göre kahverengileşme değerindeki en fazla değişim $900 \mathrm{~W}$ güç değerinde yapılan kurutma işlemi olurken en az değişim ise $360 \mathrm{~W}$ güç değerinde yapılan kurutma işleminde olduğu belirlenmiştir. Polatc1 ve Tarhan (2009), mikrodalga gücünün artması ile kahverengileşme indeksi değerinde azalmanın olduğu ve uygulanan en yüksek güç değerinde ise kahverengileşme değerinin en fazla değiştiğini belirlemiş̧lerdir. Taşova (2016), sıcaklık kontrollü mikrodalga ile yaptığ 1 elma kurutma çalışmasında sıcaklık değerinin artması ile taze ürüne göre kahverengileşme değerinde sürekli bir azalma olduğu belirlenmiştir.

\subsection{Efektif difüzyon (Deff) değeri}

Yenidünya meyvesinin uygulanan kurutma şartlarında belirlenen efektif difüzyon değerleri çizelge 8'de verilmiştir. Çalışmada güç değerinin artması ile efektif difüzyon değerinin arttığı belirlenmiştir. En yüksek efektif difüzyon değeri $900 \mathrm{~W}$ güç değerinde $6,66 \times 10-6 \mathrm{~m}^{2} \mathrm{~s}^{-1}$ olarak belirlenirken en düşük efektif difüzyon değeri ise $360 \mathrm{~W}$ güç değerinde $2,28 \times 10-6 \mathrm{~m}^{2} \mathrm{~s}$ ${ }^{1}$ olarak belirlenmiștir.

Çizelge 8. Yenidünya meyvesinin kurutma şartlarındaki efektif difüzyon değerleri

\begin{tabular}{cc}
\hline $\begin{array}{c}\text { Mikrodalga ile } \\
\text { Kurutma }\end{array}$ & $\begin{array}{c}\text { Efektif Difüzyon }\left(\mathrm{D}_{\text {eff }}\right) \text { Değerleri } \\
\left(\mathrm{m}^{2} \mathrm{~s}^{-1}\right)\end{array}$ \\
\hline $360 \mathrm{~W}$ & $2,28 \times 10^{-6}$ \\
$540 \mathrm{~W}$ & $4,28 \times 10^{-6}$ \\
$720 \mathrm{~W}$ & $5,37 \times 10^{-6}$ \\
$900 \mathrm{~W}$ & $6,66 \times 10^{-6}$ \\
\hline
\end{tabular}

Literatürde bazı ürünlerin uygulanan kurutma şartları altındaki efektif difüzyon değerlerinin belirlendiği çalışmalar yapılmıştır. Aloe vera $50-95{ }^{\circ}$ Csıcaklık aralığında değişen kurutma şartları altındaki efektif difüzyon değerlerinin 5,30-17,33×10-10 $\mathrm{m}^{2} \mathrm{~s}^{-1}$ aralığında değiş̧tiği belirlenmiş̦tir. Kurutma havası sicaklık değerlerinin artmasıyla ürünün efektif difüzyon değerlerin de arttığı ifade edilmiştir. Bu durum konvektif şartlarda mikrodalgaya göre uzaklaşan nemin daha yavaş olmasından kaynaklandığ düşünülmektedir (Miranda ve ark., 2009).Patatesin mikrodalga bantl kurutucuda 1500 $\mathrm{W}$ ve $2100 \mathrm{~W}$ güç değerlerinde üç farklı bant hızında kurutulduğunda ürünün efektif difüzyon değerlerinin $2.958 \times 10-7-3.587 \times 10-6 \mathrm{~m}^{2} \mathrm{~s}^{-1}$ aralığında değiştiği belirlenmiştir. Yenidünya meyvesine göre kıyaslandığında değerlerin yakın olduğu görülmektedir. Ancak uygulanan güç değerlerinin daha yüksek olmasından dolayı efektif difüzyon değerinin de yenidünya meyvesine göre daha büyük olması beklenirken, patatesin yenidünya meyvesine göre aynı şartlar altında daha düşük efektif difüzyon değerine sahip olmasından kaynaklandığı düşünülmektedir (Çelen ve ark., 2015). Zeytin pirinasının mikrodalga ile $170-540 \mathrm{~W}$ güç değerlerinde yaptığı kurutma çalışmasında efektif difüzyon değerlerinin 3,55-20,47x $10-9 \mathrm{~m}^{2} \mathrm{~s}^{-1}$ aralığında değiştiği belirlenmiştir. Yenidünya meyvesine göre aynı güç değerlerin daha düşük değerler aldığı ve bu durum zeytin pirinasından uzaklaşan nem oranının daha yavaş olmasından kaynaklandığı düşünülmektedir (Sadi ve Meziane, 2015).Patlıcanın mikrodalga ile $180-720 \mathrm{~W}$ güç değerlerinde yaptığı kurutma çalışmasında efektif difüzyon değerlerinin $1,75-21,66 \times 10-8 \mathrm{~m}^{2} \mathrm{~s}^{-1}$ aralı̆̆ında değiştiği belirlenmiştir. Bu durum yenidünya meyvesine göre aynı güç değerlerinde patlıcandan daha yavaş nemin uzaklaşmasından kaynaklandığı düşünülmektedir (Kutlu ve İşçi, 2016).

\section{Sonuç}

Çalışmada mikrodalga ile kurutulan yenidünya meyvesinin kuruma karakteristikleri, renk değerleri, en uygun ince tabakalı kuru modelleri ve uygulanan kurutma şartları altındaki efektif difüzyon değerleri belirlenmiștir.

$\mathrm{Bu}$ kurutma şartları altında yenidünya meyvesi kurutulduğunda elde edilebilecek sonuçlar kısaca;

Mikrodalga gücünün ürünün kurumasındaetkili bir kriter olduğuve güç değerinin artması ile kuruma süresinin azalacağı belirlenmiştir. Belirlenen bu güç değerleri altında en uzun kuruma 28 dakikaile $360 \mathrm{~W}$ güç değerinde belirlenirken,en kısa kurumanın 10 dakika ile $900 \mathrm{~W}$ güç değerinde olacağı belirlenmiştir. Belirlenen değerlere göre yenidünya meyvesi kroma değeri açısından $360 \mathrm{~W}$ güç değerinde kurutulursa daha renk tonunda kurutulmuş ürünler elde edilebileceği belirlenmiştir. Kurutma işlemlerini kontrol etmek veya yeni bir kurutucu geliştirmek için yenidünya meyvesinin belirlenen kurutma şartlar altında en uygun ince tabakalı matematiksel kurutma modelinin Midilli-Küçük modelinin seçilmesinin uygun olduğu belirlenmiştir. Ayrıca yenidünya meyvesinin yapılan bu kurutma şartlar altındagüç değerinin artması ile efektif difüzyon değerini $\operatorname{artt1ğ} 1$ ve $2.28 \times 10^{-6} \mathrm{~m}^{2} \mathrm{~s}^{-1}$ ile $6.66 \times 10^{-6} \mathrm{~m}^{2} \mathrm{~s}^{-1}$ arasinda değişen değerler alabileceği belirlenmiştir.

\section{Kaynaklar}

Abbasi, N.A., Akhtar, A. ve Hussain, A., 2013. Maintaining Quality Of Loquat (Eriobotrya Japonica Lindl.) Fruit After Harvest. Pak. J. Bot., 45(1): 247-251.

Akhtar, A., Abbasi, N. ve Hussain, A., 2010. Effect Of Calcium Chloride Treatments On Quality Characteristics Of Loquat Fruit During Storage. Pak. J. Bot., 42 (1): 181188.

Alibaş, İ., 2012a. Asma Yaprağının (Vitis vinifera L.) Mikrodalga Enerjisiyle Kurutulması ve Bazı Kalite Parametrelerinin Belirlenmesi. Tarım Bilimleri Dergisi. 18: 43-53.

Alibaş İ., 2012b. Microwave drying of strawberry slices and the determination of the some quality parameters. Journal of agriculture machinery science, 8(2): 161-170. 
Alibaş, İ., 2015. İnce tabaka mango dilimlerinin mikrodalga tekniği ile kurutulması. Anadolu Tarım Bilim. Derg. 30: 99-109.

Cao, S., Zheng, Y., Wang, K., Rui, H., Tang, S., 2009. Effect of 1- methylcyclopropene treatment on chilling injury, fatty acid and cell wall polysaccharide composition in loquat fruit. J Agric Food Chem., 57: 8439-8443.

Crank, J., 1979. The mathematics of diffusion. Oxford university press, London.

Çelen, S., 2010. Mikrodalga ve Vakum Kurutucuda Bazı Gıda Ürünlerinin Kurutulması Ve Modellenmesi. Trakya Üniversitesi Fen Bilimleri Enstitüsü Doktora Tezi.

Çelen, İ.H., Çelen, S., Moralar, A., Buluş, H.N., Önler, E., 2015. Mikrodalga Bantlı Kurutucuda Patatesin Kurutulabilirliğinin Deneysel Olarak İncelenmesi. Electronic Journal of Vocational Colleges, Özel Sayı, 5769.

Çelen, S., Haksever, A., Moralar, A., 2017. The Effects of Microwave Energy to the Drying of Apple (Gala) Slices. Karaelmas Fen ve Müh. Derg., 7(1): 228-236.

Ghasemnezhad, M., Nezhad, M.A., Gerailoo, S., 2011. Changes in Postharvest Quality of Loquat (Eriobotrya japonica) Fruits Influenced by Chitosan. Hort. Environ. Biotechnol., 52(1): 40-45.

Ercişli, S., Gözlekçi, S., Şengül, M., Hegedus, A., Tepe, S., 2012. Some physicochemical characteristics, bioactive content and antioxidant capacity of loquat (Eriobotrya japonica (Thunb.) Lindl.) fruits from Turkey. Scientia Horticulturae, 148: 185-189.

Karim, M.A., Hawlader, M.N.A., 2005. Mathematical modelling and experimental investigation of tropical fruits drying. İnt. J. Heat Mass Transfer, 48: 4914-4925.

Kaya, A., Kamer, M.S., Şahin, H.E., 2015. Trabzon Hurmasının (Dıospyros Kakı L.) Kuruma Davranışının Deneysel İncelenmesi. G1da 40 (1): 15-21. doi: 10.15237/gida.GD14047.

Kutlu, N., İşci, A., 2016. Farklı Kurutma Yöntemlerinin Patlıcanın Kurutma Karakteristikleri Üzerine Etkisi ve Kurutmanın Matematiksel Modellenmesi. Akademik G1da 14 (1): 21-27.

Lin S, Eriobotrya japonica (loquat), in The Encyclopedia of Fruit andNuts, ed. by Janick $\mathrm{J}$ and Paull R. CABI, Wallingford, pp. 642-651.

Lin, S., Sharpe, R.H., Janick, J., 1999. Loquat: botany and horticulture. Horticult. Rev. 23: 233-276.

McGuire, R.G., 1992. Reporting of objective color measurements. Hort Science, 27, 1254 - 1255.

Miranda, M., Maureira, H., Rodriguez, K., Vega-Galvez, A. (2009), Influence of temperature on the drying kinetics, physicochemical properties, and antioxidant capacity of
Aloe Vera (Aloe Barbadensis Miller) gel, Journal of Food Engineering, 91: 297-304.

Pareek, S., Benkeblia, N., Janic, J., Cao, S. ve Yahia, E., 2014.Postharvest physiology and technology of loquat (Eriobotrya japonica Lindl.) fruit. J Sci Food Agric., 94: 1495-1504

Pisalkar, P. S., Jain, N. K. ve Jain, S. K., 2011. Osmo-air drying of aloe vera gel cubes. Journal of food science and technology-mysore, 48(2): 183-189.

Saberian, H., Amooi, M. ve Esfahani, Z.H., 2014. Modelling of vacuum drying of loquat fruit. Nutrition ve Food Science, 44: 24-31.

Sadi, T., Meziane, S., 2015. Mathematical modelling, moisture diffusion and specific energy consumption of thin layer microwave drying of olive pomace. International Food Research Journal, 22(2): 494-501.

Sao, X., Zhu, Y., Cao, S., Wang, H., Song, Y., 2013. Soluble Sugar Content And Metabolism As Related To The HeatInduced Chilling Tolerance Of Loquat Fruit During Cold Store. Food Bioprocess Technol., 6: 3490-3498.

Singh, B., Gairola, S., Kumar, D., Gupta, V., Bansal, P., 2010. Pharmacological potential of Eriobotrya japonica-an overview. Int. Res. J. Pharm., 1: 95-99.

Taşova, M., 2016. Sicaklık Kontrollü Bir Mikrodalga Kurutucu Geliştirilmesi Ve Performansının Belirlenmesi. Yüksek Lisans Tezi, Gaziosmanpaşa Üniversitesi, Tokat.

Yağcıoglu, A., 1999. Tarımsal Ürünleri Kurutma Tekniği. Ege Üniversitesi ziraat fakültesi yayınları No: 536. Bornova, İzmir.

Yang, S.L., Sun, C.D., Wang, P., Shan, L.L., Cai, C., 2008. Expression Of Expansin Genes During Postharvest Lignifications And Softening Of 'Luoyangqing' And ' Baisha' Loquat Fruir Under Different Storage Conditions. Postharv. Biol. Technol., 49: 46-53.

Yoğurtçu, H., 2016. Determination of Drying Kinetics of Tunceli Garlic with Microwave Drying Technique. Tarım Bilimleri Dergisi, 22: 237-248.

$\mathrm{Xu}, \mathrm{H}$. ve Chen, H., 2011. Commercial quality major bioactive compound content and antioxidant capacity of 12 cultivars of loquat (Eribotrya japonica Lindl.) fruits. J. Sci. Food Agric., 91: 1057-1063.

Xu, H., Yang, Y., Xie, L., Li, X., Feng, C., Chen, J., 2014. Involvement Of Multiple Types Of Dehydrins İn The Freezing Response İn Loquat (Eriobotrya japonica). PLoS One, 9:87575.

Zakipour, E. ve Hamidi, Z., 2011. Vakum Drying Characteristic Of Some Vegetables. İranian Journal of Chemistry and Engineering, 4(30): 97-105.

Zhou, C.H., Xu, C.J., Sun, C.D., Li, X. ve Chen, K.S., 2007. Carotenoids İn White-And Red-Fleshed Loquat Fruits. J Agric Food Chem., 55: 782. 